\title{
LIMIT CYCLES IN DISCONTINUOUS GENERALIZED LIÉNARD DIFFERENTIAL EQUATIONS
}

\author{
Zouhair Diab ${ }^{1}$ \\ ${ }^{1}$ University of Tebessa
}

July 10, 2020

\begin{abstract}
The goal of this paper is to study the number of limit cycles that can bifurcate from the periodic orbits of a linear center perturbed by nonlinear functions inside the class of all generalized Liénard diøerential equations allowing discontinuities. In particular our results show that for any $n 1$ there are diøerential equations of the form $x^{*}+f\left(x_{;} x_{-}\right) x_{-}+x_{+}+\operatorname{sgn}\left(x_{-}\right) g(x)=0$, with $\mathrm{f}$ and $\mathrm{g}$ polynomials of degree $\mathrm{n}$ and 1 respectively, having $[\mathrm{n}=2]+1$ limit cycles, where [] denotes the integer part function.
\end{abstract}

\section{Hosted file}

doc ML.pdf available at https://authorea.com/users/296719/articles/468633-limit-cycles-indiscontinuous-generalized-li\%C3\%A9nard-differential-equations

\section{Hosted file}

doc ML.tex available at https://authorea.com/users/296719/articles/468633-limit-cycles-indiscontinuous-generalized-1i\%C3\%A9nard-differential-equations 